\title{
Social Media Engagement and Public Health Communication: Implications for Public Health Organizations Being Truly "Social”
}

\author{
Amy Burnett Heldman, MPH, ${ }^{1}$ \\ Jessica Schindelar, MPH, ${ }^{1}$ \\ James B. Weaver III, PhD, $\mathrm{MPH}^{2}$
}

\begin{abstract}
Social media are designed to be engaging, but often are used as a mechanism by public health organizations and practitioners for mass information dissemination rather than engaging audiences in true multi-way conversations and interactions. In this article we define and discuss social media engagement for public health communication. We examine different levels of engagement for public health communication and consider the potential risks, benefits, and challenges of truly embracing the social component in public health practice. Some implications of engagement for public health communication via social media are addressed, and recommendations for future work and research are proposed.
\end{abstract}

Key Words: Social media, engagement, public health communication, public health

Recommended Citation: Heldman AB, Schindelar J, Weaver JB III. Social media engagement and public health communication: implications for public health organizations being truly "social". Public Health Reviews. 2013;35: epub ahead of print.

\section{INTRODUCTION}

Inarguably, social media have become an integral part of the public health conversation. The number of users and the voracity with which these users

\footnotetext{
${ }^{1}$ Centers for Disease Control and Prevention, Office of the Associate Director for Communication, Division of Public Affairs, Atlanta, GA, USA.

${ }^{2}$ Centers for Disease Control and Prevention, Office of the Associate Director for Communication, Office of the Director, Atlanta, GA, USA.
}

Corresponding Author Contact Information: Amy Burnett Heldman at evd4@cdc.gov; Centers for Disease Control and Prevention, 1600 E. Clifton Road, MS-E21, Atlanta, GA 30033, USA. 
consume information on social media sites continues to grow. Data ${ }^{1}$ show that 67 percent of internet users participate in social networking sites, and Facebook, the most popular social media platform, reported 1.1 billion monthly active users earlier this year. ${ }^{2}$

How social media can be harnessed to best achieve public health outcomes is a topic of much discussion and study in the public health community. Recent studies ${ }^{3-6}$ have examined the effectiveness of and implications for using social media and other digital media in health promotion and disease prevention endeavors, finding mixed and, in some cases, less than compelling evidence of efficacy in impacting public health. Others have issued calls to action for increased study and focus on social media and other emerging technologies as part of a comprehensive public health communication strategy. ${ }^{6-8}$

Unfortunately, as Neiger et al. ${ }^{9}$ have noted, there is very little evidence to indicate that social media are being adequately used by public health organizations in ways that leverage the ability to have meaningful conversations with our audiences. Similarly, Chou et al., ${ }^{4}$ following a review of public health interventions using Web 2.0 and social media, concluded there is a "need to harness the participatory nature of social media." Public health practitioners, it would seem, must embrace the unique characteristics and functionality of social media to engage members of digital communities in interactive conversations about health; a communication approach that we have labeled social media engagement.

In this discussion, we define social media as the collection of digital channels and tools (e.g., Facebook, Twitter, and YouTube) used for public health communication. One defining characteristic of all social media is their potential to facilitate engagement-the interactive, synchronous communication and collaboration among numerous participants via technology. There is a multi-way communication, at the same time but in different places, functionality available through social media, enabling public health organizations to move from basic information dissemination typical of traditional mass media to a fully interactive information sharing dialogue.

While many public health organizations, such as the United States Centers for Disease Control and Prevention (CDC), the US Food and Drug Administration (FDA), the World Health Organization (WHO), the American Public Health Association (APHA), and others ${ }^{10-13}$ have established a social media presence, the role of social media engagement in advancing public health communication work at the organizational level is infrequently discussed. In this article, we look at social media engagement through a public health lens to develop a definition of social media 
engagement for public health endeavors, to discuss the importance of such engagement, and to make practical recommendations for implementing social media engagement in public health communication.

\section{SOCIAL MEDIA ENGAGEMENT: IMPORTANCE FOR PUBLIC HEALTH}

Before we discuss the opportunities presented by social media engagement, it is important to better understand the unique characteristics of social media that make these important channels for public health communication work. The $\mathrm{CDC}^{14}$ has identified the following characteristics that make social media viable channels for public health communication efforts:

- Social media can work best when integrated with traditional public health communication channels. While some think social media can be used as independent, stand-alone channels disparate from "traditional" health communication tactics, many of the strategies that work for social media are those that work for and have been proven to be effective for traditional health promotion or other mass communication efforts. $3,15,16$ Just because social media channels are "new" does not mean that the established body of evidence from years of health communication and promotion research is null and void. Social media work best when integrated into a health communication strategy to support overarching communication goals and objectives.

- Through social media, we can target and reach diverse audiences. Just as some audiences may prefer to receive health information via print materials, or from their peers, some audiences prefer to receive health information and communicate with public health organizations online. Indeed, 59 percent of US adults who use the internet reported that they have looked online for health information in the past year, ${ }^{17,18}$ with 35 percent indicating they had gone online specifically to understand an emerging health condition. With the number of social media users steadily growing, ${ }^{1}$ social media present an opportunity to reach audiences who may prefer to receive health information through these channels.

- Social media allow us to share public health information in new spaces. Social media allow us to share relevant content in new and emerging channels, test how our messages resonate in different spaces, and provide opportunities for multiple exposures to messages. Through the use of social media channels, public health organizations can share relevant content where users are already spending their time. As public 
health communicators, we can connect "starting where the people are"19 by using social media. ${ }^{20,21}$ Sharing health content in new spaces allows public health communicators to potentially tap into the large audiences of social media channels. For example, explosive growth in the use of Instagram, a photo-sharing social media site, among African American and Hispanic audiences ${ }^{1}$ affords a great opportunity to determine the best ways within the channel to target public health messaging for these demographic groups.

- We can listen and collect feedback in real-time. A unique characteristic of social media is that we can learn more about our audiences by paying attention to social media conversations at the aggregate level as they are unfolding in real-time. Just as social media have been used to inform and support public health surveillance and epidemiology, ${ }^{22-24}$ so too can social media be used to scan publicly-available social media content to inform communication activities. Social media monitoring tools allow public health organizations to learn more about what diverse audiences are saying regarding public health topics, identify information gaps, and adjust messaging accordingly. Social media give us insights into what health information may be important and interesting to users, in the moment. This real-time aspect of social media is a key component to ensuring that our communication efforts are relevant, meaningful, and useful to our audiences.

- Social media permit us to increase direct engagement. Finally, due to the multi-way, interactive functionality that is inherent to these platforms, social media can allow us to increase direct engagement to maintain and increase trust and credibility, among other engagement benefits that are the subject of further discussion in this paper.

We acknowledge the dual nature of social media as a tool both for mass message dissemination to audiences and for multi-way interactions with sizable audience segments. It is this interactive potential that defines social media engagement: lack of interaction is simply broadcasting. As public health communication practitioners, we often focus our efforts on using social media for dissemination. It is not clear, however, if we are using social media to engage with our audiences, and considering what engagement means for the field of public health. What exactly does social media engagement mean for public health communications? 


\section{DEFINING SOCIAL MEDIA ENGAGEMENT FOR PUBLIC HEALTH}

In the simplest of terms, social media engagement is social-it is participatory and reciprocal, lending itself to conversations and interactions between and among a public health organization and its diverse audiences via social media channels. Social media has been characterized as mutually beneficial for public health organizations and their audiences to connect to each other in ways that promote a "common good". ${ }^{9}$ Drawing from these characteristics, we arrive at a social media engagement definition that frames engagement as a multi-way interaction between and among an organization and digital communities that could take many forms, using social media channels to facilitate that interaction; health messaging is shared in a way that creates opportunities for information to be acted on by the audience, thereby opening a dialogue with the organization that allows both parties to work collaboratively to address issues affecting the health and well-being of the audience.

Though new social media channels and terminology have emerged relatively recently in the public health communication area, engagement is not a new concept. Discussions on ways to interact with target audiences and communities for the benefit of public health pre-date social media ${ }^{25,26}$ and are worth noting due to characteristics shared with social media. Public health defines community engagement as "the process of working collaboratively with and through groups of people affiliated by geographic proximity, special interest, or similar situations to address issues affecting the well-being of those people."27 Similarly, community building, as described by Minkler and Wallerstein, ${ }^{26}$ is "an orientation to the ways in which people who identify as members of a shared community engage together in the process of community change."

Social media engagement is fast emerging as a way to complement and support the existing evidence and best practices from the community engagement and community building perspectives. The Clinical and Translational Science Awards Consortium ${ }^{25}$ has discussed the potential of "community-mediated forms of communication," including social media, in engaging the public, because social media provide opportunities for interaction and discussion, build and sustain networks, build trust, mobilize communities, and support engagement, among other benefits. Social media are ideally suited for online community building by facilitating broad and deep interaction and engagement with target audiences. Public health community engagement, when moved online to social media channels, is characterized by interaction with multiple, self-selected communities. 
These online communities are non-traditional in that they are not defined by space, time, or geography. Rather, online communities are formed by individuals who organize themselves around a given issue. A large, active online community has formed, for example, around global efforts to improve access to clean water. Advocates have successfully used social media to raise awareness of water issues around the world and improve access to clean water. ${ }^{28}$

\section{PRINCIPLES OF SOCIAL MEDIA ENGAGEMENT FOR PUBLIC HEALTH}

Social media strategists have proposed several multi-stage models and levels of social media engagement. ${ }^{9,29-31}$ Drawing from these examples as well as our own experiences as public health practitioners implementing social media engagement strategies in a large organization, we propose seven principles that should be part of an organization's public health communication social media strategy. Each item represents a different level of agency and public interaction, with each requiring different degrees of organizational commitment (e.g., staffing, financial resources, and infrastructure development). Of these principles, no single way of engaging the public is right or wrong or better than another. Detailed below are the seven principles of social media engagement that public health organizations should strive to incorporate into their communication goals and management strategies.

- Listening to social media conversations. One of the most basic forms of engagement is to use social media to identify the health information needs of users. This can be accomplished through the use of social media monitoring tools. ${ }^{32}$ Public health organizations should use social listening to identify what people are saying on social media channels about priority public health topics, find gaps in messaging, and understand what people care about to inform a cohesive, comprehensive communication strategy. This will help to ensure that messages align with the needs of our audiences. The ability to listen and respond with relevant messaging demonstrates that public health organizations are paying attention and developing messaging accordingly. As they listen, organizations should follow established best practices for social media to ensure that privacy is protected. ${ }^{33}$

- Engaging with influencers and their conversations. By monitoring social media, public health organizations can also identify key partners and public health influencers driving online conversations on health topics of interest and develop mutually beneficial relationships with 
them. Influencers can include both organizations and individuals ${ }^{34}$ and exhibit the characteristics of credibility, persistence in convincing others, and ability to drive conversations so that others take notice of the topic or idea and show support. ${ }^{35}$ For example, conducting outreach to bloggers who discuss public health topics that align with an organization's priorities could be an effective way to engage on Twitter. ${ }^{36,37}$ Once identified, organizations can engage with influencers to discuss ways to promote messaging on shared communication goals to increase the reach of public health communications. Identifying and determining appropriate ways to engage with social media influencers and establish a reciprocal social media relationship can be a simple and powerful way to increase the reach of messaging and align with other public health influencers. Caution is advised, however, when reaching out to and/or partnering with social media influencers as they often achieve such a status because they are perceived as independent and trustworthy. Public health organizations must be sensitive to the possible risk of influencers becoming or being seen as "spokespersons" for their organizations. . $^{38,39}$

- Responding to questions or comments received via social media channels. Social media channels are a powerful tool for customer service and can demonstrate that organizations are paying attention to the conversations. At the public health organization level, this should include responding to health-related questions and comments-both negative and positive-received through organizational social media channels. Organizations should fully embrace this aspect of social media engagement and encourage quick replies. Establishing a nimble, responsive infrastructure allows an organization to thoughtfully and efficiently provide feedback to such social media inquiries.

- Create opportunities for users to engage with your organization, and for your users to engage with each other. Organizations should identify opportunities to connect directly with users, and to facilitate discussions between users. These "small acts of support"15 may have a "ripple effect" across social media sites, leading to increased engagement among other users. For example, many public health organizations have hosted Facebook and Twitter chats, which are scheduled social media events that allow direct, real-time interaction between social media followers and organization experts and leaders. These events allow users to connect directly with an organization, share resources and information on a public health topic, and talk to each other during the event. Simple content approaches, such as asking users to comment on social media material, can also demonstrate a commitment to engaging with social media users. 
- Welcome and solicit user-generated content. Encourage users to share their stories, participate in message creation, and collaborate on ideas or strategies that can be shared on an organization's social media channels to increase users' engagement and reaction to public health messages. Challenge.gov, the US federal government's contest- and challengehosting site, shares challenges that encourage public participation. ${ }^{40}$ For organizations that do not have the capacity to host a large-scale usergenerated content program, soliciting user-generated content can be as simple as asking users to submit photos related to a health campaign, or share their personal stories through an organization's social media channels. For example, the federal "Facing AIDS"41 social media initiative supports the National HIV/AIDS Strategy's efforts to combat stigma associated with HIV and promote HIV testing. Social media users are encouraged to take pictures of themselves holding signs with personalized messages about why they are "Facing AIDS." Users can then upload and share the photos on social media with their communities.

- Create opportunities to integrate online and offline engagement. Integrating social media engagement with in-person experiences allows engagement in both the virtual and real world, and gives committed social media users the opportunity to gain exclusive access to events and opportunities. Examples of online/offline engagement include NASA Social, ${ }^{42}$ which provides in-person opportunities for users who currently engage on NASA social media accounts, such as meet and greet sessions and behind the scenes events to connect with NASA scientists. The American Red Cross also offers training to individuals on using social media on behalf of the Red Cross. During disasters, these Digital Disaster Volunteers report back to the Red Cross social media team and "monitor, engage, and report on activity surrounding specific disasters."

- Leveraging social media for community engagement. As discussed above, using social media to enhance community engagement activities could be useful to public health, though more work in this area is needed to determine how best to seek input and feedback from the public and stakeholders on public health issues through social media. Organizations could consider implementing simple engagement activities in lieu of a comprehensive social media community engagement strategy. For example, the Substance Abuse and Mental Health Services Administration's online discussion forum, designed "as part of the agency's continuing efforts to increase opportunities for public engagement, collaboration and participation," could be used and adapted as a model mechanism to solicit input. ${ }^{44}$ 
A recent study illustrates how a mix of engagement activities can result in a quantifiable outcome, and shows promise for leveraging social media engagement for public health impact. ${ }^{45}$ In May 2012, the social networking platform, Facebook, allowed users to share organ donation status on their Facebook timelines; that status was shared with the users' Facebook friends. Taking engagement a step further, users could then officially register online as an organ donor with their state's Department of Motor Vehicles. Engaging with Facebook as a partner, capitalizing on the platform's ability to allow users to post and share information with their Facebook friends, and providing a simple way to make the organ donor pledge "real" resulted in a 21.2-fold increase in new online donor registrations on the day the initiative began. While the number of online donor registrations decreased throughout the 12 day campaign, registration rates remained elevated. As the authors note, this model holds great potential for determining the best ways to apply social media engagement efforts to other public health communication work.

\section{CONSIDERATIONS FOR SOCIAL MEDIA ENGAGEMENT FOR PUBLIC HEALTH}

Social media engagement, in whatever form it takes, is an important area of study and further discussion for public health communication-how do we "put social in social media?" Existing and emerging social media channels and tools that allow users to connect with public health organizations, and to connect with one another, should not be dismissed as a passing fad or trend-social media have become ubiquitous. As Mays et al. ${ }^{45}$ note, "One point that is very clear is that...channels that enable extensive networks of consumers to actively engage one another... are not disappearing any time soon." Fox ${ }^{46}$ echoes this sentiment: "The social life of health information is robust. The online conversation about health is being driven forward by two forces: 1) the availability of social tools and 2) the motivation, especially among people living with chronic conditions, to connect with each other." Social media are not going away, nor are the expectations that if an organization has a social media presence, the organization will be engaging on it. Public health communicators should work to determine how best to harness the unique characteristics of social media to advance communication.

There is also an expectation of direct relationships with organizations and individuals through social media. Social media allow users unprecedented access to public health organizations and leaders. A growing number of public health leaders are establishing an official spokesperson presence in social media. The directors of the CDC, the National Institutes 
of Health, and other public health leaders have all built robust Twitter audiences. Social media users expect individuals on social media to listen, respond, and interact in a personal way that reflects both the leader's and the organization's personality and priorities. Seeing the person behind the public health organization improves trust and credibility over time, by allowing users to talk to and with the person versus interacting with an impersonal organization.

Another reason, perhaps the most important, that engagement needs to be embraced is the potential impact on health behavior change. At its very core, engagement requires that users do something with informationlisten, share, create, act, respond, ask. As public health communicators, we ultimately want our audiences to take action to improve their health by practicing healthy behaviors. Evidence that engaging in online communications positively impacts people's health is limited ${ }^{4,9,47}$; this does not mean that the potential for impact is not there, just that more inquiry is needed. ${ }^{48,49}$ The effects of engagement need to be better studied to determine how we can foster and encourage healthy behaviors through these channels.

\section{CHALLENGES IN SOCIAL MEDIA ENGAGEMENT FOR PUBLIC HEALTH}

Just as there are many benefits to using social media for engagement purposes, there are risks and challenges that must be discussed, analyzed, and addressed in the public health community.

- Loss of Message Control. Potential risks of and fears related to social media engagement include loss of control of the message, giving credence and credibility to "junk science," and reputational concerns. ${ }^{6}$ Concerns about negative comments misdirecting and reshaping the message and conversation, or "online incivility," ${ }^{50}$ are valid. These concerns should be factored into the management of an organization's social media engagement strategy and also speak to the need to proactively engage with social media influencers to encourage a thoughtful dialogue on public health topics where common ground can be found.

- Shift to "Direct-to-Consumer Engagement". An additional challenge is our default public health perspective; in public health we are trained to look at populations in the aggregate. We are not always comfortable in thinking about one-on-one interaction on the individual level. How to mitigate these risks and concerns, while also leveraging social media engagement, is an important area of inquiry for the field to move forward. While there are certain risks inherent in social media engagement, there could be more risk in not engaging. Establishing clear, responsive 
approval processes for social media engagement will help public health organizations manage risk and ensure the accuracy and quality of information. Risks can be recognized and assuaged to truly unlock the potential of social media engagement.

- Resource Allocation (Monetary and Personnel). Public health organizations interested in developing a social media engagement strategy should be mindful of the level of effort needed. In general, our experience shows that the higher the level of engagement, the more effort needed ${ }^{51}$ to adequately and effectively maintain a consistent, coordinated engagement approach. Organizations must be willing to commit the time to provide appropriate oversight of the effort, routinely monitor and respond to feedback and questions received, identify engagement opportunities, review data from engagement efforts, and adjust strategies accordingly. While there are tools and systems available to help manage an organization's social media presence, they cannot replace the human element required to make decisions and judge appropriateness. Planning documents and guidelines ${ }^{51,52}$ are available to aid public health organizations in assessing whether integrating social media into existing communication strategies is feasible and determining if the outcomes justify the financial and work allocations.

- Assessing Impact on Public Health Outcomes. A further challenge is quantifying the impact and demonstrating the value of social media engagement. Responding to a question on Facebook or asking users for feedback on public health issues results in what public health outcome? Korda and $\operatorname{Itani}^{3}$ point out that evaluation and measurement of social media engagement need to be better studied to determine if meaningful engagement is actually occurring. Jürgens ${ }^{53}$ notes the many opportunities and methodological challenges of evaluating and studying social media, as does Moorhead, ${ }^{47}$ whose systematic review found that many social media studies have limited methods and are exploratory and descriptive in nature, reporting eight gaps in the literature that need to be addressed, including studies with larger sample sizes and more robust methodologies. What is needed are evidence and data that demonstrate the effectiveness of social media engagement on public health outcomes. As Regenberg ${ }^{54}$ states in the context of bioethics public engagement, "Given the typical orientation of the research community, arguments in favor of investing in social media engagement will be strongest when backed by data." The federal government and others have proposed a series of social media metrics ${ }^{55,56}$ in an attempt to standardize social media measurement, but more study and conversations are needed to refine and establish an effective set of measurement tools. 


\section{RECOMMENDATIONS FOR ADVANCING SOCIAL MEDIA ENGAGEMENT FOR PUBLIC HEALTH}

Identifying social media challenges moves us one step closer to having increased confidence in our ability to effectively manage and leverage social media engagement, and learn from those who are tackling the issues head on. More case studies and sharing of best practices for public health organizations on social media engagement will illuminate ways to mitigate challenges. The CDC Social Media Council, the guiding body in setting the agency's social media strategy, has identified engagement as an area of focus in 2013. Others must join in working together to advance the practice of social media engagement in support of the public's health.

Now is the time to define, implement and evaluate a public health communication social media engagement approach that is research-based and data-driven. It takes effort to do social media engagement well, and we need to channel our time and resources effectively by using evidence-based approaches. To that end, we should not limit our scientific inquiry to public health. We must learn from the available literature and unpublished work on civic, community, and public engagement, as well as look to other disciplines, including journalism, risk communication, and private sector social media efforts, among others, to apply any relevant lessons learned to social media engagement. Perhaps most importantly, we must continue to understand the needs of our users and determine which engagement tactics are the most effective in meeting those needs.

Conversations in social media about public health topics are happening whether we participate or not. As Ledford says, "...the social component of behavior and communication has influenced what we as communicators and marketers do... We now engage our audiences directly at an unprecedented level, stimulated by and resulting in increased audience expectations of engagement." ${ }^{57}$ The question is how do we participate and engage most effectively? We must be nimble; the flow of information is moving faster than ever, and as public health communicators we must be able to respond and engage in real-time or risk being left behind, for example, during a public health emergency or crisis. ${ }^{58,59}$ We risk losing our audience if we do not engage; others will step in to fill the information gap. Thus, it is worth investing the time in studying social media engagement for public health communication. As Ledford again notes, "Just as in face-to-face relationships, the media will require time and commitment to be effective." 57

The most important thing we can do is engage with a thoughtful, datadriven approach. Engagement is not a strategy for public health social 
media communication work. It's an organization's core value, philosophy, and culture. It's an acknowledgement and a commitment to our users- the people in "public" health-that they matter, that we care and are listening, and that their opinion matters. It benefits public health communication to maximize the social media functionality that allows us to interact with the people we serve. Social media engagement lends a human element to our communications. Engagement keeps us from being perceived as tone deaf or insensitive to the concerns and needs of our audiences-if we are engaged, truly engaged, we are constantly listening, responding, interacting, learning, and growing.

Without conversations, we run the risk of becoming, as US Senator for the state of New Jersey, Cory Booker noted of the US federal government's social media efforts in early 2013, “....an announcement system, like you used to listen to in class...that's not interaction, that's not collaboration." ${ }^{60}$ The potential of social media engagement for advancing public health is great; as Teusch and Fielding ${ }^{8}$ point out, "Public health needs a strong, effective voice to be successful in a world full of social media... The tools of public health are changing. Older models of health education are inadequate. Information is not sufficient to change behaviors." Social media provide opportunities to connect with the communities we serve that should not be squandered; an opportunity for public health communicators to, as Dorothy Nyswander encouraged, "start where the people are."19

As a field, public health communicators need to step further into social media engagement and embrace the social nature of social media. To advance the practice of social media engagement we propose the following action steps, focusing on strategy, capacity, and evaluation. First, public health communicators must determine how social media engagement principles can best support an organization's overall communication objectives. The organization's communication infrastructure must be evaluated to assess its capacity to implement social media engagement and establish procedures to facilitate the process. Communicators should identify the key metrics and measures that will show the value of social media engagement for their organization and drive ongoing improvements in engagement. And perhaps most importantly, as Ratzan ${ }^{48}$ notes, “... leadership of multiple sources from different sectors...can establish credible entities that build upon an ethical, theoretical, scientific, and evidence-based foundation to advance accurate information and knowledge that leads to appropriate action and sustainable responses." In short, we must collectively work together to address how best to leverage social media, specifically the ability to engage with our audiences, to improve public health outcomes. 
Acknowledgements: Thank you to Jay Dempsey and Catherine Jamal from the Centers for Disease Control and Prevention and Valerie Daniel from Northrup Grumman for their thoughtful review and comments.

Disclaimer: The findings and conclusions in this report are those of the authors and do not necessarily represent the official position of the Centers for Disease Control and Prevention/the Agency for Toxic Substances and Disease Registry.

Conflicts of Interest: None declared.

\section{REFERENCES}

1. Duggan M, Brennar J. Pew Research Center's internet and American life project. The demographics of social media users - 2012. 14 February 2013. Available from URL: http://www.pewinternet.org/Reports/2013/Social-media-users.aspx (Accessed 18 April 2013).

2. Facebook. Newsroom. Available from URL: https://newsroom.fb.com/KeyFacts (Accessed 17 July 2013).

3. Korda H, Itani, Z. Harnessing social media for health promotion and behavior change. Health Promot Pract. 2013;14:15-23.

4. Chou WS, Prestin A, Lyons C, Wen K. Web 2.0 health promotion: reviewing the current evidence. Am J Public Health. 2013;103:e9-18.

5. Chou SW, Hunt YM, Beckjord, El B, Moser RP, Hesse BW. Social media use in the United States: implications for health communication. J Med Internet Res. 2009;11:e48.

6. Lefebvre RC, Bornkessel, AS. Digital social networks and health. Circulation. 2013;127:1829-36.

7. Martin-Moreno JM, Apfel F, Sanchez, JLS, Galea, G, Zsuzsanna J. The social nature of chronic noncommunicable diseases and how to tackle them though communication technology, training, and outreach. J Health Commun. 2011; 16:94-106.

8. Teutsch SM, Fielding JE. Rediscovering the core of public health. Annu Rev Public Health. 2013;34:287-99.

9. Neiger BL, Thackery R, Burton SH, Giraud-Carrier CG, Fagen, MC. Evaluating social media's capacity to develop engaged audiences in health promotion settings: Use of Twitter metrics as a case study. Health Promot Pract. 2013;14:157-62.

10. Thackeray R, Beiger BL, Smith AK,Van Wagenen SB. Adoption and use of social media among public health departments. BMC Public Health. 2012; $12: 242$.

11. Waters RD, Williams JM. Squawking, tweeting, cooing, and hooting: analyzing the communication patterns of government agencies on Twitter. J Public Affairs. 2011;11:353-63.

12. Park H, Rodgers S, Stemmie J. Health organizations' use of Facebook for health advertising and promotion. J Interactive Advertising. 2011;12:62-77. 
13. Avery E, Lariscy R, Amador E, Ickowitz T, Primm C, Taylor A. Diffusion of social media among public relations practitioners in health departments across various community population sizes. J Public Relations Res. 2010;22: 336-58.

14. U.S. Centers for Disease Control and Prevention. Health Communicator's Social Media Toolkit. July 2011. Available from URL: http://www.cdc.gov/ socialmedia/tools/guidelines/pdf/socialmediatoolkit_bm.pdf (Accessed 6 May 2013).

15. Abroms LC, Lefebvre RC. Obama's wired campaign: Lessons for public health communication. J Health Comm. 2009;14:415-23.

16. Mangold WG, Faulds DJ. Social meida: the new hybrid element of the promotion mix. Bus Horiz. 2009;52:357-65.

17. Fox S, Duggan M. Pew Research Center's internet and American life project. Health online 2013. 15 January 2013. Available from URL: http://pewinternet. org/Reports/2013/Health-online.aspx (Accessed 28 March 2013).

18. Weaver JB III, Mays D, Linder G, Eroglu D, Fridinger F, Bernhardt, JM. Profiling characteristics of internet medical information users. J Am Med Inform Assoc. 2009;16:714-22.

19. Nyswander D. Education for health: some principles and their application. Health Edu Monogr. 1956;14:65-70 .

20. Bernhardt JM. Health education and the digital divide: building bridges and filling chasms. Health Edu Res. 2000;15:527-31.

21. Wang CC. The future of health promotion: TalkinTM technology blues. Health Promot Pract. 2000;1:77-80.

22. Kemble SK, Westbrook A, Lynfield R, Board A, Koktavy N, et al. Foodborne outbreak of Group A Streptococcus Pharyngitis associated with a high school dance team banquet-Minnesota, 2012. Clin Infect Dis. 2013;57:344-8.

23. Brownstein JS, Clark C, Freifeld BS, Madoff LC. Digital disease detectionharnessing the web for public health surveillance. N Engl J Med. 2009:360: 2153-7.

24. St. Louis C, Zorlu G. Can Twitter predict disease outbreaks? BMJ. 2012;344: e2353.

25. Clinical and Translational Science Awards Consortium, Community Engagement Key Function Committee Task Force on the Principles of Community Engagement. Principles of Community Engagement, Second Edition. 2011. Available from URL: http://www.atsdr.cdc.gov/communityengagement/pdf/ PCE_Report_508_FINAL.pdf (Accessed 18 April 2013).

26. Minkler M, Wallerstein NB. Improving health through community organization and community building. In: Glanz K, Rimer BK, Lewis FM, (editors). Health Behavior and Health Education. Theory, Research, and Practice. 3rd Edition. San Francisco: Josey-Bass; 2002. pp. 279-311.

27. U.S. Centers for Disease Control and Prevention. Principles of community engagement. Second Edition. CDC/ATSDR Committee on Community Engagement. 1997, Atlanta, GA. 
28. Fox Z. World water day campaigns making a splash on the web. 22 March 2013. Available from URL: http://mashable.com/2013/03/22/world-water-daysocial-media/ (Accessed 18 April 2013).

29. Papworth L. 7 levels of social media engagement. 11 March 2011. Available from URL: www.socialmediatoday.com (Accessed 5 March 2013).

30. Tuvell Communications. The 5 levels of social media engagement. 16 August 2011. Available from URL: http://www.slideshare.net/tuvelcomms/the-5levels-of-social-media-engagement (Accessed 28 April 2013).

31. Paul S. The 5 stages of social media engagement. 13 February 2012. Available from URL: http://whatworkswhere.com/index.php/2012/global/the-5-stagesof-social-media-engagement-part-1-of-5-traditional/ (Accessed 28 April 2013).

32. Dyer P. 50 top tools for social media monitoring, analytics, and management. 13 May 2013. Available from URL: http://socialmediatoday.com/node/145746 (Accessed 17 July 2013).

33. CIO Council. Privacy Best Practices for Social Media. July 2013. Available from URL: https://cio.gov/wp-content/uploads/downloads/2013/07/PrivacyBest-Practices-for-Social-Media.pdf (Accessed 24 October 2013).

34. Booth N, Matic JA. Mapping and leveraging influencers in social media to shape corporate brand perceptions. Corporate Communications. 2011;16:184-91.

35. Biran O, Rosental S, Andrea J, McKeown K, Rambow O. Detecting influencers in written online conversations. Proceedings of the 2012 Workshop on Language in Social Media (LSM 2012). pp. 37-45.

36. Daniel, V. Secrets to successful influencer engagement for dynamic Twitter chats. National Conference on Health Communication, Marketing, and Media. 20-22 August 2013. Oral presentation, abstract 33733.

37. Jones R. Using CDC Twitter chats to engage key influencers and extend reach. National Conference on Health Communication, Marketing, and Media. 7-9 August 2012. Oral presentation, abstract 31843.

38. Web, J. Five characteristics of an influencer. 19 October 2011. Available from URL: http://www.meeklabs.com/social-marketing/social-media/five-character istics-of-an-influencer/ (Accessed 8 May 2013).

39. Freberg K, Graham K, McGaughey K, Freberg L A Who are the social media influencers? A study of public perceptions of personality. Public Relat Rev. 2011;37:90-2.

40. U.S. General Services Administration. Challenge.gov. Available from URL: http://challenge.gov/ (Accessed 31 March 2013).

41. U.S. Department of Health and Human Services. AIDS.gov. Facing AIDS. Available from URL: http://facing.aids.gov/ (Accessed 18 April 2013).

42. National Aeronautics and Space Administration. Connect and collaborate with NASA. Available from URL: http://www.nasa.gov/connect/social/index.html (Accessed 16 March 2013).

43. American Red Cross. Red Cross University: digital disaster volunteer training. Available from URL: http://redcrosschat.org/disaster-digital-volunteer-training/ (Accessed 16 March 2013). 
44. Substance Abuse and Mental Health Services Administration. 20 March 2011. Available from URL: http://www.samhsa.gov/about/feedback.aspx (Accessed 15 March 2013).

45. Mays D, Weaver JB III, Bernhardt JM. New media in social marketing. In: Hastings G, Angus K, Bryant C, (editors). The Sage Handbook of Social Marketing. London: Sage; 2011. pp. 178-90.

45. Cameron AM, Massie AB, Alexander CE, Stewart B, Montgomery RA, Benavides NR, Fleming GD, Segev, DL. Social media and organ donation registration: the Facebook effect. Am J Transplant. 2013;13;2059-65.

46. Fox S. The social life of health information 2011. 12 May 2011. Available from URL: http://www.pewinternet.org/Reports/2011/Social-Life-of-Health-Info. aspx (Accessed 20 March 2013).

47. Moorhead SA, Hazlett DE, Harrison L, Carroll JK, Irwin A, Hoving C. A new dimension of health care: systematic review of the uses, benefits, and limitations of social media for health communication. J Med Internet Res. 2013;15:385.

48. Ratzan SC. Our new "social" communication age in health. J Health Comm. 2011;16:803-4.

49. Cheung CMK, Thadani DR. The impact of electronic word-of-mouth communication: a literature analysis and integrative model. Decision Support Systems. 2012;54:461-70.

50. Anderson A, Brossard D, Scheufele DA, Xenos MA, Lawig P. The "nasty effect:" online incivility and risk perceptions of emerging technologies. J Comput Mediat Commun. 2013; epub ahead of print.

51. U.S. Centers for Disease Control and Prevention. CDC social media tools, guidelines, \& best practices. 17 April 2013. Available from URL: www.cdc. gov/socialmedia/Tools/guidelines (Accessed 16 July 2013).

52. U.S. General Services Administration. Digital strategy. Available from URL: http://www.howto.gov/digital-strategy (Accessed 16 July 2013).

53. Jürgens P. Communities of communication: making sense of the "social" in social media. J Technol Hum Serv. 2012;30:186-203.

54. Regenberg AC. Tweeting science and ethics: social media as a tool for constructive public engagement. Am J Bioeth. 2010;10:30-1.

55. U.S. General Services Administration. Social media metrics for Federal agencies. 19 April 2013. Available from URL: http://www.howto.gov/socialmedia/using-social-media-in-government/metrics-for-federal-agencies (Accessed 19 April 2013).

56. \#SMMStandards. 2012. About \#SMMStandards. Available from URL: www. smmstandards.com (Accessed 24 July 2013).

57. Ledford CJ. Changing channels: a theory-based guide to selecting traditional, new, and social media in strategic social marketing. Soc Mar Q. 2012;18:17586. 
58. U.S. Centers for Disease Control and Prevention. Crisis and emergency risk communication. 2008. Available from URL: http://emergency.cdc.gov/cerc/ pdf/cerc_guide_basic.pdf (Accessed 15 March 2013).

59. Merchant RM, Elmer S, Lurie N. Integrating social media into emergencypreparedness efforts. N Engl J Med. 2011;365:289-91.

60. Huffington Post. Cory Booker at SXSW: government needs to reform social media strategy. 10 March 2013. Available from URL: http://www. huffingtonpost.com/2013/03/10/cory-booker-sxsw_n_2850442.html (Accessed 16 March 2013) 